\title{
Análise Quantitativa do Colágeno no Paramétrio e Cúpula Vaginal de Mulheres com e sem Prolapso Uterino
}

Autor: Claudia Cristina Takano

Orientador: Prof. Dr. Manoel J.B.C. Girão

Tese apresentada à Universidade Federal de São Paulo - Escola Paulista de Medicina para obtenção do Título de Mestre em Ginecologia em 12 agosto de 1999.

Avaliamos a quantidade de colageno no paramétrio e na cúpula vaginal de mulheres com e sem prolapso uterino. Estudamos 23 pacientes que foram submetidas à histerectomia abdominal com diagnóstico de leiomioma uterino, e 33 pacientes com prolapso uterino, que foram submetidas à histerectomia vaginal. Durante o procedimento cirúrgico retiramos fragmentos do paramétrio e da cúpula vaginal, e processamos o material para análise histológica utilizando a coloração de picrosirius. Para a quantificação das fibras de colágeno utilizamos o sistema de análise digital de imagem por computador (Imagelab - Softium). Comparamos inicialmente a quantidade de colágeno no paramétrio e na cúpula vaginal. Não houve diferença no colágeno dos dois locais nas pacientes sem prolapso uterino, enquanto no grupo com prolapso uterino, a quantidade de colágeno no paramétrio foi significativamente menor do que na cúpula. Quando comparamos a quantidade de colágeno dos dois grupos, obser- vamos quantidade significativamente menor de colágeno no paramétrio e na cúpula vaginal das pacientes com prolapso uterino em comparação com as pacientes sem prolapso uterino. Subdividimos as pacientes dos dois grupos consoante o estado menopausal. Registramos menor quantidade de colágeno no paramétrio das pacientes com prolapso, quer no menacme, quer na pós-menopausa, não havendo diferença entre estes dois subgrupos. Já na cúpula vaginal não houve diferença entre os grupos. Concluímos que as pacientes com prolapso uterino apresentam menor quantidade de colágeno no paramétrio do que na cúpula vaginal, e menor quantidade nos dois locais, quando comparamos com as pacientes sem prolapso. A diferença no paramétrio foi independente do estado menopausal.

Palavras-chave: Prolapso uterino. Colágeno. Menopausa.

\section{Relação Entre a Atividade Proliferativa do Epitélio e a Resposta Angiogênica Estromal em Neoplasias Intra-epiteliais do Colo Uterino}

Autor: Maria Angélica Maia Gaiotto

Orientador: Profa Dra. Julisa Chamorro Lascasas Ribalta

Tese apresentada ao Curso de Pós-Graduação em Ginecologia do Departamento de Tocoginecologia da Universidade Federal de São Paulo - Escola Paulista de Medicina para obtenção do título de Mestre em Ginecologia em 4 de novembro de 1999.

Para que haja crescimento tumoral é necessário a ocorrência de atividade proliferativa e angiogênica. Como o método imuno-histoquímico é satisfatório para a quantificação dos vasos e da proliferação do epitélio, nós o utilizamos através dos marcadores imunohistoquímicos anti-CD34 e anti-PCNA para quantificarmos os vasos neoformados e atividade proliferativa na neoplasia intra-epitelial. Utilizamos 16 pacientes com NIC III e 16 com NIC II (alto grau), 21 pacientes com NIC I (baixo grau) e ainda 11 pacientes com colos normais (grupo controle). A avaliação das lâminas foi feita por dois observadores, concomitantemente, em 10 campos consecutivos, com aumento de $100 \mathrm{x}$ e de $400 x$, na região de maior densidade vascular (CD34) e na região de maior atividade proliferativa (PCNA). As médias obtidas com o emprego do anti-PCNA em neoplasias intra-epiteliais foram: $78,19 \%$ (NIC III), $52,09 \%$ (NIC II), 33,26\% (NIC I) e 4,65\% (grupo controle), enquanto com o marcador vascular anti-CD34 as médias foram: 199,13 vasos (NIC III), 162,00 vasos (NIC II), 111,67 vasos (NIC I) e 124,45 vasos (grupo controle). Os resultados demonstram que os dois marcadores, o anti-PCNA e anti-CD34, são úteis na avaliação da atividade proliferativa e angiogênica, respectivamente. O uso do anti-PCNA permite diferenciar as neoplasias intra-epiteliais com mais clareza do que o anti-CD34.

Palavras-chave: Neoplasias intra-epiteliais cervicais. Angiogenese. Proliferação celular. 